\title{
Feasibility and Effectiveness of Different Models of Team-Based Learning Approaches in STEMM-Based Disciplines
}

\author{
Maria Parappilly $^{1}$ (D) . Richard John Woodman ${ }^{2} \cdot$ Sharmil Randhawa $^{1}$
}

Published online: 4 October 2019

(C) The Author(s) 2019

\begin{abstract}
This study presents findings from three different disciplines in STEMM (Science, Technology, Engineering, Mathematics and Medicine) and across different models of student-focused teaching. Specifically, we assessed the feasibility and effectiveness of flipped classroom approaches combined with team based learning (TBL), and TBL alone within STEMM, particularly in the disciplines of Physics, Engineering and Medicine across different year levels. TBL activities were incorporated into undergraduate Physics and Engineering cohorts, with students from a diverse range of majors and backgrounds and a graduate level Doctor of Medicine (MD) cohort. Quiz scores from the Physics cohort were significantly improved following TBL, exam scores from the engineering cohort were more evenly distributed than pre-TBL quiz scores and students in the medical cohort had higher quiz scores when working within teams rather than alone. Qualitative survey responses from both the physics and engineering cohorts indicated that students felt TBL was positive and increased their understanding of key concepts. Informal feedback from medical students following TBL classes was also very positive and students demonstrated obvious engagement. Comparisons for pre- versus post-TBL quiz scores for Physics, for pre-TBL quartile versus exam scores in Engineering and for Team versus Individual learning quiz scores in Medicine all provide evidence of effective student engagement and performance. The observation study suggests that TBL is a feasible and effective method of student-focused learning within STEMM. More rigorously designed studies are now required to further explore these findings.
\end{abstract}

Keywords Team-based learning $\cdot$ Group work $\cdot$ Student engagement $\cdot$ STEMM

\section{Introduction}

Traditionally, tertiary education has tended to focus on teacher-centred methods of teaching and these approaches are still to be found in many University lecture theatres within

Maria Parappilly

maria.parappilly@flinders.edu.au

1 College of Science and Engineering, Flinders University, Adelaide, Australia

2 College of Medicine and Public Health, Flinders University, Adelaide, Australia 
Australia and globally. Whilst such approaches have some merit in allowing full control of students, and the material and concepts delivered, there is a great risk that students become bored and disengaged, which results in them still missing key facts or concepts. Consequently, there is now a major drive in many tertiary institutions in Australia and also worldwide towards using student-centred approaches to teaching wherever possible.

Active learning is a pedagogical process whereby students are directly involved in the learning process, i.e. they are engaged in the material to be studied through various meaningful activities (Bonwell and Eison 1991). Students will interact with one another, ask questions and at the same time also learn independently. The aim is that they become more interested and engaged in the topic which leads to greater overall enjoyment in the learning process and ultimately better learning outcomes. There is now evidence from STEMM (Science, Technology, Engineering, Mathematics and Medicine) disciplines that these active learning approaches do indeed increase both engagement as well as learning discipline (Boud et al. 2001; Freeman et al. 2014; Georgiou and Sharma 2015; Hake 1998; Landis 2000; Parappilly et al. 2013, 2015; Scicluna et al. 2015; Springer et al. 2013; Tai et al. 2014) content.

Several different approaches to active learning strategies have been used including peer learning, problem-based learning (PBL) and team-based learning (TBL). Peer learning has been used in the science fields of Engineering, Physics and Medicine (Boud et al. 2001; Landis 2000; Scicluna et al. 2015; Tai et al. 2014). Peer learning (Hains-Wesson 2007) engages students and enhances learning through a range of activities including the use of small learning groups (Burke 2011), self reflection and peer assessment. In a large study conducted by Springer et al. (2013), researchers explored the main effects of small group learning on three attributes among STEM undergraduates: achievement, persistence and attitudes. The study reported that various forms of small group learning produced higher achievement test scores, more positive student attitudes and higher levels of student persistence.

It is argued that groups have more information than a single individual. In addition, students who are involved in 'group work' have been shown to develop a deeper understanding of the subject matter and increased problem-solving skills and perform better academically (Cooper 1990; Davis 1993). In peer learning, whilst there is no direct intervention of teachers, their role is to define the learning objectives of the required activity, as well as forming the student groups, which then is capable of fostering peer teaching among students (Johnson et al. 2007; Boud et al. 2001). Peer learning can also help students acquire develop educational resilience and acquire a range of transferable key skills such as self-reflection, time management, organisational and team skills which are highly valued work-ready skills (Topping 2005).

TBL is an established model of group work which aims to improve students' achievement to apply discipline-related content (Michaelsen et al. 2002). Its activities give students time for active engagement, opportunities for problem-solving and application of content. As a result, it provides them with early practice at professional competencies and also develops teamwork skills (Betta 2015). The four essential elements of TBL are as follows: formation and management of groups, student accountability, frequent and timely feedback and design of appropriate group assignments (Michaelson and Sweet 2008). The three phases of TBL include the following: advanced individual preparation, readiness assurance and group application (Parmelee and Michaelson 2010). In TBL, the instructor pre-identifies all of the required content for the three phases of the TBL. This paper focuses on using a flipped TBL model to improve student learning outcomes in three STEMM-based disciplines.

The flipped classroom is a pedagogical approach that inverts traditional notions of content delivery and learning activities (Hamdan et al. 2013; Lage and Platt 2000). It consists 
of teaching and learning by interactivity that involves both students and their teachers. This blended learning method engages students with the content focusing on key concepts prior to class, allowing face-to-face time for in-class group-based interactive learning activities that clarify concepts through application, problem-solving, analysis and immediate feedback ((Anderson et al. 2001; Karanicolas and Snelling 2010). The flipped classroom be implemented by replacing as small as a lecture or as large as the entire curriculum delivery (Hurtubise et al. 2015).

The findings of a 5-year study conducted by Kalman et al. (2015) that involved around one thousand physics students at two Canadian universities found 'flipped classrooms' improve student learning gain and engagement and their thinking abilities. Many studies found the flipped classroom as one of the best pedagogies used in different levels of engineering education because of its potential to enhance learning by solving real-world problems and develop strong self-learning abilities among students (Ayala et al. 2017; Kerr 2015; Le et al. 2015; Yelamarthi and Drake 2015).

TBL is an effective way to structure a flipped classroom (Jakobsen and Knetemann 2017; Moffett 2015) and to promote positive student outcomes. As such, our model also followed a classroom 'flip' approach that used important elements of both TBL and Just in Time Teaching (JiTT). JiTT (Watkins and Mazur 2009) provides students with preparatory material prior to class and some questions to answer. Similar to a flipped classroom approach, the individual preparation phase of the TBL engages students with the content and key concepts prior to class (TBL Workshop). The group application phase of the TBL allows students to explore the key concepts and to solve problems in groups in a collaborative learning environment with the guidance of a teacher or instructor. Working with their peers also help them understand different approaches to problem-solving. The in-class group-based activities of TBL provide students an opportunity to question their alternative personal scientific conceptions and to learn other perspectives (Ahrensmeier et al. 2009; Kalman et al. 2010).

Given this assessment of different learning strategies and the reported advantages offered by TBL, there is now a need to assess the various strengths of different forms of TBL when implemented within the science disciplines including medicine. The focus of this study is to therefore describe the results of several different approaches to TBL that were in various STEMM disciplines (Physics, Engineering and Medicine) at Flinders University, a leading university in Australia with a reputation for excellence and innovation in teaching. We were especially interested in determining whether group learning in various different forms was associated with student experience and better learning outcomes compared with working independently.

The overall aim was to assess the effectiveness of small group learning. This was done in three separate cohorts.

1. Aim 1 (Physics cohort)

To determine if students improved their quiz scores whilst working in groups throughout the Physics topic.

2. Aim 2 (Engineering cohort)

(a) To determine whether group learning helped normalise student achievement by comparing pre-learning quiz scores with the final exam score.

(b) To determine the extent to which students agreed that group learning was a valuable exercise.

3. Aim 3 (Medicine cohort)

To compare the quiz performance between students working as individuals versus working within groups. 


\section{Method}

Within a calendar year, we trialled flipped models of teaching that utilised many different features of TBL amongst first year Engineering, Physics and first year Doctor of Medicine (MD) students, following a successful study of a TBL model for first year Physics students (Parappilly et al. 2015). The study design was retrospective using data from the three separate cohort of students. In our model, in particular for the physics and engineering cohorts, one lecture per week was replaced by a TBL activity comprising a pre-class preparation and quiz (Individual) an in-class group quiz with immediate feedback, and a group problemsolving assignment. We incorporated JiTT principles, by using the information about how students perform individually in the pre-quiz to inform the content of the group quiz and to determine which concepts would be clarified in class.

\section{TBL in Physics: Flipped TBL with Pre- and Post-quiz}

In Physics, we adopted a similar method to that described in our previous study (Parappilly et al. 2015). In this study, the students were placed in mixed ability groups based on their admissions data in comparison with the previous study, where we randomly formed permanent student groups. The cohorts in the Introductory Physics topics are comprised of students of different ages, mature ages $(>23)$ and backgrounds with vastly different previous scientific experience: for example some have studied Year 12 Physics, but most have not. In fact many of this student cohort were not enrolled in any traditional science course in senior high school. Student grouping was performed based on admissions data to help ensure the mixed characteristic of the groups enhanced learning outcomes. At least one mature-aged student and one high-achieving student were included within each group to balance the student mix equally across each group (Parappilly et al. 2018). In this topic, one of the three weekly lectures was flipped and replaced by a TBL activity. The four TBL workshops implemented were focused on energy, energy transfer, conservation of energy, electromagnetic radiation and nuclear physics.

\section{- Individual Preparation Phase}

Students engaged with the subject matter in private study, for example, by reading the chapter of their physics textbook and lecture materials, as well as prescribed online videos on their LMS. The topic material contains five units: energy, electromagnetic (EM) wavesenvironmental effects of EM radiation, global warming and climate change, the nucleus and nuclear energy and cosmology.

\section{- Readiness Assurance Phase}

Following the preparation phase held in the prior week, students independently undertook a pre-TBL quiz. The quizzes were developed using a mixture of conceptual questions and problems taken from the required reading textbooks and reference books (Giancoli 2008; Griffith and Brosing 2002; Franklin et al. 2010; Urone 2001) and questions formulated by the lecturer. This pre-class preparation and quiz ensured that all students were exposed to all major concepts to be applied within forthcoming TBL workshop to be delivered after a week's time. In the TBL workshop, students in their assigned teams re-took a subset of 
the quiz questions (the five lowest scoring problems from the pre-TBL quiz) and received immediate feedback from the lecturer.

\section{- Group Application Phase}

In the second half of the TBL workshop, each of the assigned groups completed an in-class group assignment that consisted of two problems. The aspect of flipped TBL workshop offered more in-class time for problem-solving and the focus was on the students leading the discussions, identifying and exploring problem-solving strategies, applying the core concepts learned in the preparation and readiness assurance phases. The students worked together within mixed ability groups for the entire semester.

After the workshop, students then individually undertook a post-TBL quiz. The posttests were different to the pre-tests; new questions added to the post-tests allowed students to apply concepts to new situations and better test their conceptual understanding. A total of four sets of pre-TBL and post-TBL online quizzes were completed throughout the course of the topic. Some post-TBL questions were similar to the pre-TBL questions, but we made sure that all students receive a unique question by randomising the variables in those questions to yield different answers.

\section{TBL in Engineering: Flipped TBL with Pre-quiz, Assignment, Exam and Survey}

The first year electronics topic consist of students enrolled in various engineering degrees, namely electrical, electronics, computer systems, mechanical, biomedical and civil engineering. Thus, students enrolled in this topic were not from the typical electrical or electronic streams.

The three TBL workshops implemented were focused on circuit analysis, Boolean minimisation and design of finite state machines. As part of the individual preparation phase, students had to complete an assigned preparatory work (Najdanovic-Visak 2017), which consisted of reading the required material from the textbook (Nilsson and Riedel 2014) and lecture notes. To ensure students coming to class were prepared, students had to complete an individual readiness assurance test consisting of a pre-TBL quiz on the LMS platform. The quizzes were developed by the lecturer to compliment the modules covered in the electronics topic.

In class, students worked together within groups that were formed randomly prior to the class.

As per Physics, each group worked on a subset of the pre-quiz questions, mainly focusing on those questions which were poorly done. They also received feedback from the lecturer. As part of the group application phase, students then completed a group in-class assignment.

A post-TBL quiz was not administered for this topic. However, end of semester exam scores for the topic were available for each student. At the end of the topic, students were invited to complete a 4-point Likert scale survey on the TBL classes and their preparedness for the classes. We utilised a slightly modified version of the validated instrument developed by Vasan et al. (2009) consisting of eleven statements as shown in Table 1. This is a validated survey instrument used by several health professions education researchers (Morris 2016).

\section{TBL in Medicine: Flipped TBL with Pre- and Post-quiz and Assignment}

Year $1 \mathrm{MD}$ students were taught basic principles in biostatistics over the course of two weeks that included two online lectures and one face-to-face lecture/workshop. In the first 


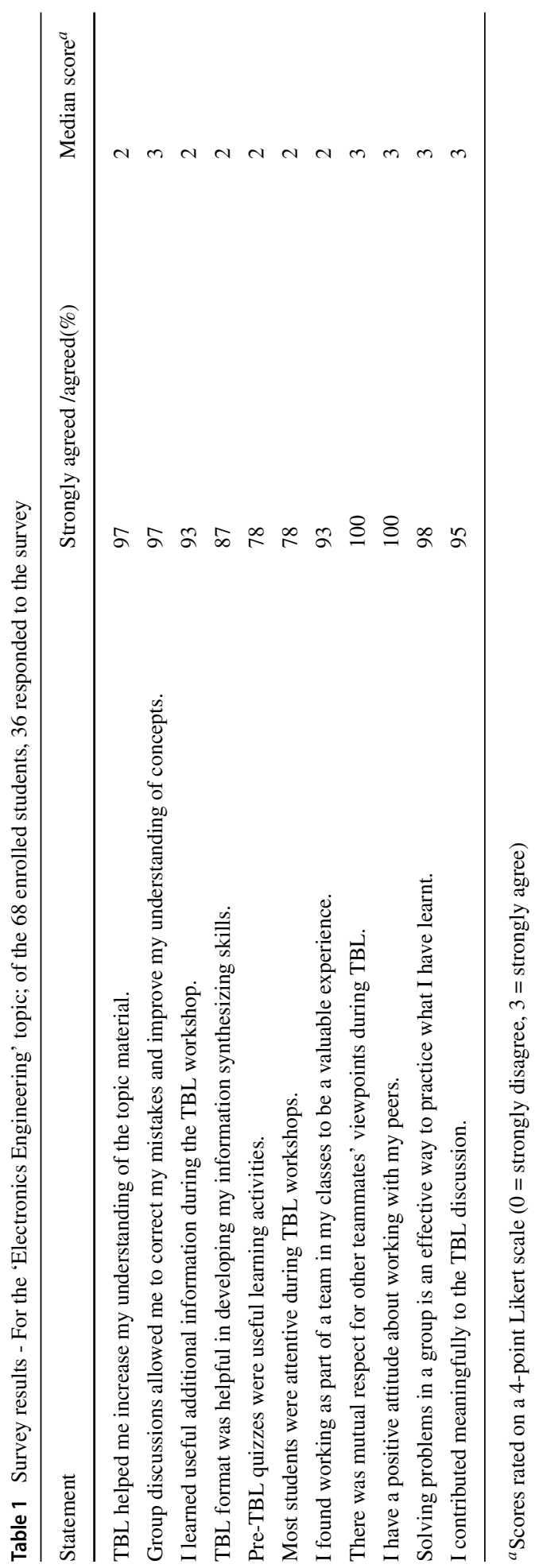


week, they completed the two short (40 min) online lectures in which they were introduced to the following:

- The different types of quantitative data used in medical research (categorical—ordinal and nominal, continuous - scale or interval, time-to-event data, e.g. mortality and survival time)

- The use of $95 \%$ confidence intervals to describe the uncertainty of data including means and regression coefficients

- The types of analysis used for assessing data, i.e. chi-squared tests for categorical data, $t$ tests, ANOVA, regression for continuous data and survival analysis, and Kaplan-Meier plots for survival analysis.

The following week, students attended a TBL lecture in which they were presented with a series of twenty questions on material related to the online lectures. They first completed these individually, and then some 15 min later, they completed the same questions, but this time in small groups of three to four students in which they discussed the questions together. At the end of the face-to-face TBL lecture, the lecturer went through the solutions to each of the twenty questions. This formed the basis of the teaching for the biostatistics. The following week, students were asked to complete an open book online multiple-choice quiz covering the same material that they had previously learnt online and in class. Importantly for TBL evidence, the students could choose to complete the quiz (a) individually but working within a group, i.e. groups of two or more students would discuss the question together but individually decide on what was the correct answer, (b) individually and working alone, i.e. the students would complete the quiz on their own without discussing the questions with other students or (c) as a group, i.e. working within in a group and providing an agreed group response. Data from this MCQ was used to assess the effectiveness of TBL in the medicine cohort; specifically, whether or not working within a group lead to higher mean scores.

\section{Statistical Analysis}

Statistical analysis was performed using Stata version 14.2 (StataCorp, College Station, TX, USA). For the physics cohort, we used a mixed effects multi-level linear regression model (Raudenbush and Bryk 2002) to account for the within-subject correlation within the data since there were up to eight measures for each subject (four pre-quiz quiz scores and four post-quiz scores). A multi-level approach (Singer and Willett 2003) is now considered the standard method for analysing data which contains repeated measures on the same individual over time. It allows incorporation of any subjects with missing data at some time points and accounts for the within-subject correlation of the data between assessment points by treating each individual as a 'random' effect. The TBL period (Pre- versus Post-) and the Quiz number (class one, class two, class three or class four) were included as 'fixed' effects. Each subject therefore had eight separate records included within the dataset. The subject ID $(1,2,3$. . etc.) was included as a random intercept and the dependent variable was the quiz score. In addition to testing significance for the fixed factors (Quiz number and pre-versus post-), we also tested for an interaction between these factors to determine if the effect of the TBL (pre- versus post-TBL quiz score) differed across the four classes. We used the 'mixed' command within Stata for the analysis.

For the engineering cohort, we compared the pre-quiz TBL scores with exam scores to see if there was a levelling out of achievement between the pre-quiz TBL and the exam. To do this, students were first grouped into four groups based on the pre-TBL quiz score 
quartiles (i.e. $25 \%$ of subjects in each group according to lowest scores in group 1 and highest scores in group 4). We then used one-way ANOVA to assess differences in the exam scores between these four groups. The pre-TBL quartile group was the factor and the exam score was the dependent variable.

For the MD cohort of students, we also used one-way ANOVA to compare the postTBL online quiz scores according to the method in which the students completed the quiz (individually, individually within a group, or as a group response). The quiz score was the outcome (dependent variable) and the independent variable (factor) was the group (method) the student belonged to. Boxplots were created to assist in visualising each set of results.

\section{Ethics Approval}

This project had ethics approval from Flinders University (Project Number: 5757 SBREC).

\section{Results}

\section{Improved Student Learning in Physics}

A total of 46 students were enrolled in the topic. Figure 1 depicts the results of the pre-TBL and post-TBL test of all four quizzes that were delivered to the physics students throughout the topic. The post-quiz scores were significantly higher than the pre-quiz scores $(p<0.001$ for each), and the improvements were similar for each of the four different quizzes (see Fig. 1) when students were placed in mixed ability groups.

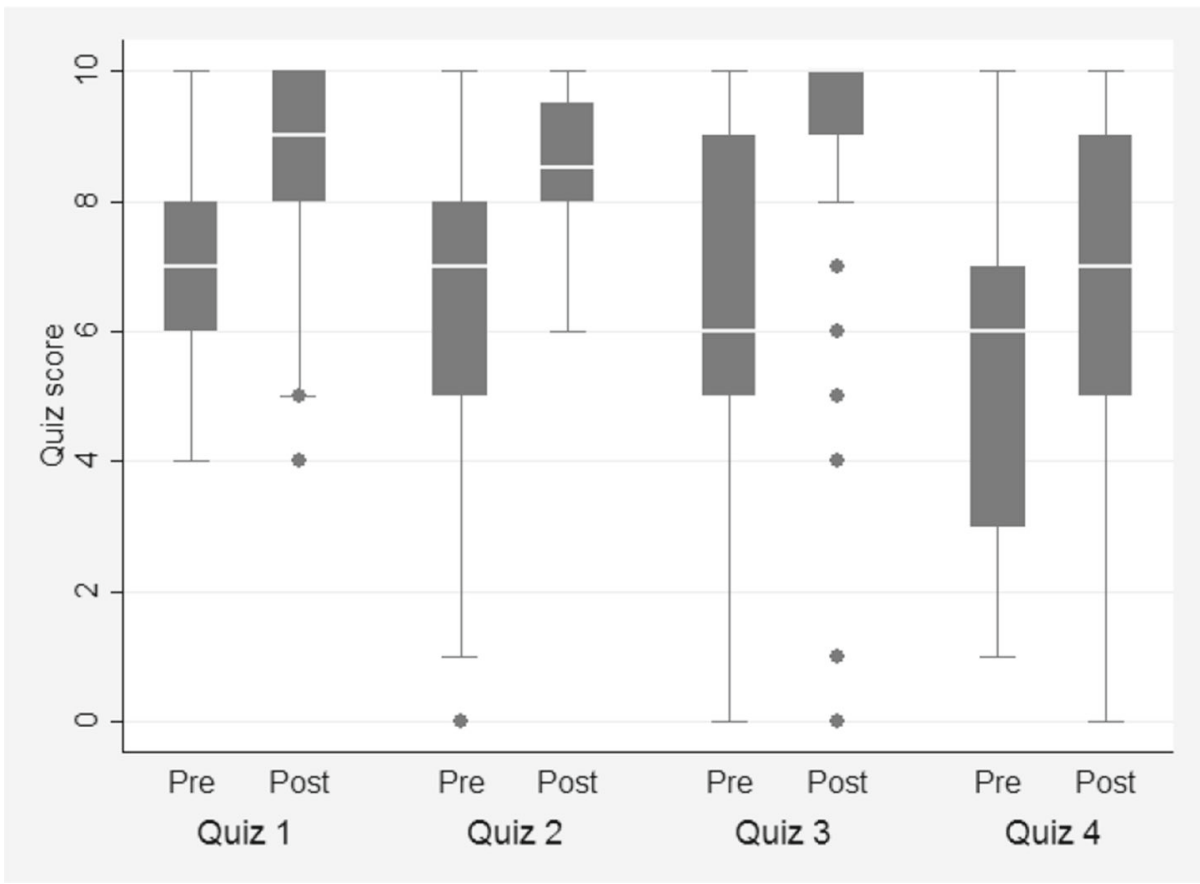

Fig. 1 Boxplot showing Mean scores for the pre-post -test results of all four physics quizzes. Outliers are those subjects further than 1.5 times the IQR from the 25 th or 75 th percentile and are depicted as dots 


\section{Improved Student Learning in Engineering}

Within the engineering cohort, there were 16, 23, 17 and 24 students in the four quartiles based on their pre-TBL quiz scores (Fig. 2). There was a wide range of achievement across individuals as assessed by Pre-Quiz 1 (mean, $3.5 \pm 3.0$; range $0--10$ ). Whilst this was also reflected in the exam scores, only the highest pre-quiz quartile group was significantly different to the lowest pre-quiz quartile group ( $p<0.001$ ) (Fig. 3). Thus, the differences in exam scores between students were narrower than expected based on the pre-TBL quiz scores with some degree of overlap between the four pre-quiz quartiles, suggesting that group work had resulted in a degree of levelling across the various student abilities.

\section{Improved Student Learning in Medicine}

A total of 150 medical students completed the post-TBL quiz. The number of students completing the quiz in the various possible categories of response options was (a) an individual working within a group $(n=29)$, (b) individual working alone $(n=102)$ and (c) working in a group and providing an agreed group response $(n=19)$. In one-way ANOVA, there was a significant difference in the mean grade across the 3 groups $(p<0.001)$ as shown in Fig. 4. The mean $( \pm$ SD) grade for those students who submitted their own answer whilst working within a group was significantly higher than those that worked alone $(16.5 \pm 2.0$ versus $13.8 \pm 3.0 ; p<0.001)$. Similarly, those submitting an agreed group response within a team group also scored significantly higher than those that worked and answered alone

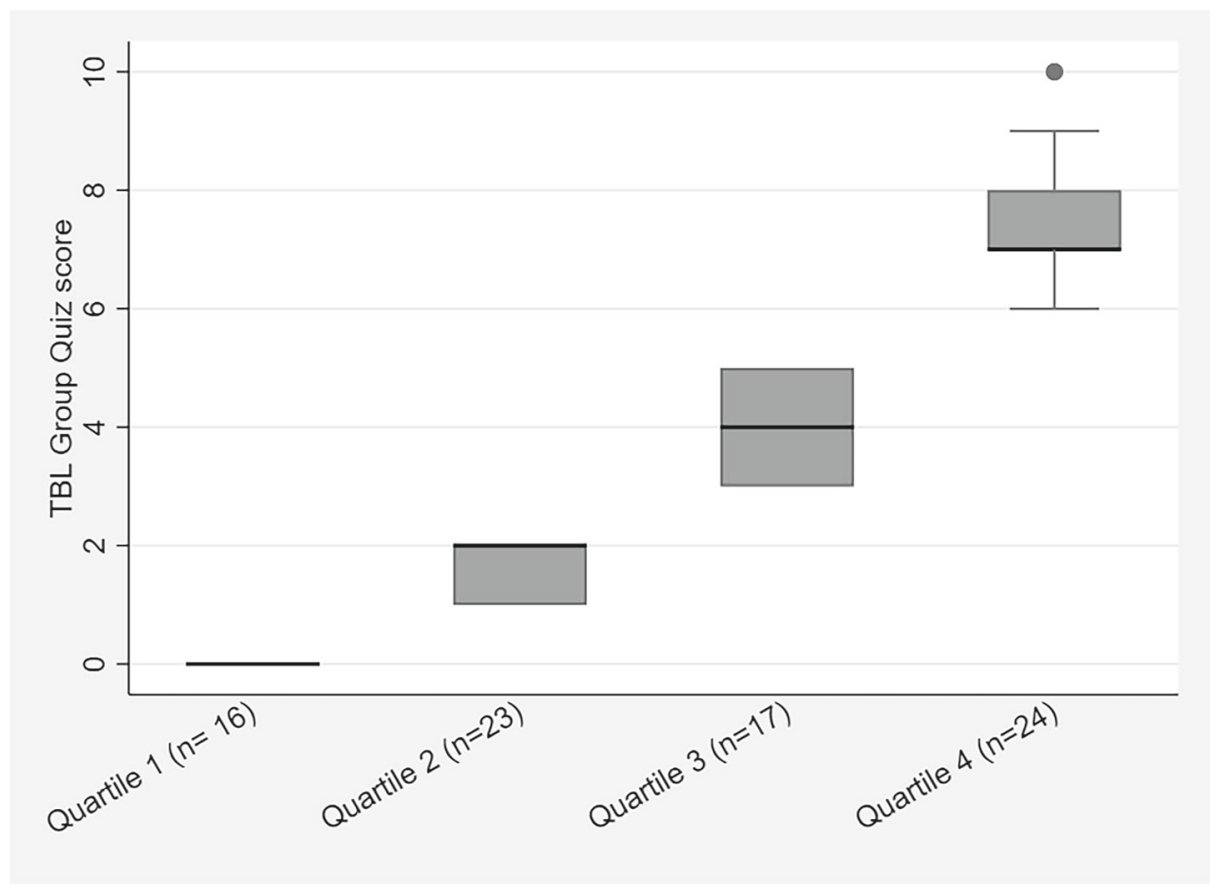

Fig. 2 Boxplot showing the pre-TBL quiz scores by quartiles for the engineering cohort. Outliers are those subjects further than 1.5 times the IQR from the 25 th or 75 th percentile and are depicted as dots 


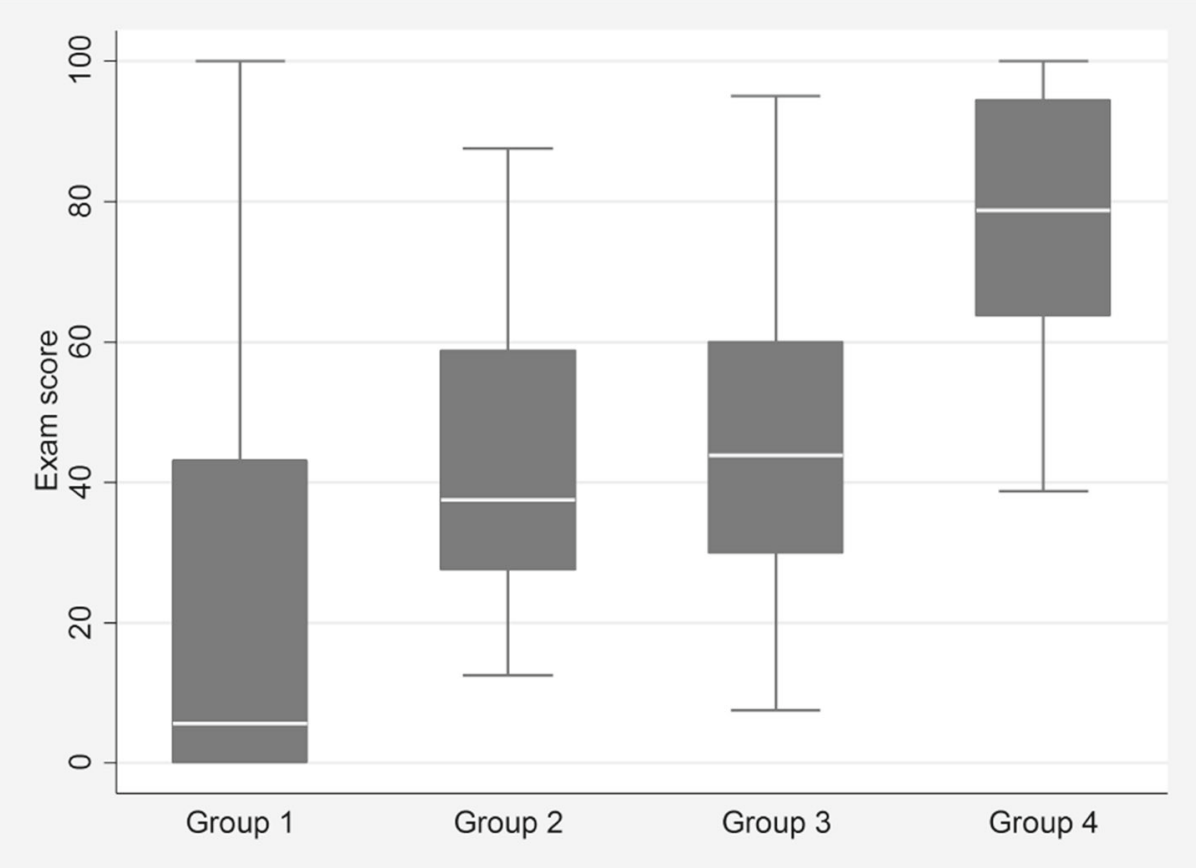

Fig. 3 Boxplot showing exam scores for pre-TBL quiz quartile groups for the engineering cohort

$(16.4 \pm 2.2, p<0.001)$. Thus, individuals that worked in a group during the quiz had significantly higher scores than those working and answering alone.

\section{Student's Reactions to TBL in Engineering}

The evaluation of the Engineering survey results showed overwhelmingly positive feedback about the TBL activities and how it helped them in their learning process. In the open-ended section of the survey, students reported that the group application phase of TBL was central to their learning. Sample student comments received for the best aspect of TBL include the following:

'The group based learning and tutorials was when I found myself gaining the most.'

'The group based learning was definitely the most beneficial to me as it forced us to actually do questions unlike the lectures and tutorials.'

Of the 68 enrolled students, 36 responded to the survey (53\% response rate). Table 1 summarises the responses to the eleven statements. Responses to most statements suggested that TBL helped students in their learning process. In particular, a high proportion of students $(97 \%)$ felt that TBL helped them to increase their understanding of the topic material. Ninety-eight percent of the students strongly agreed that solving problems in a group is an effective way to practice what they have learned. Most students indicated that they found working as part of a team, in their classes, a valuable experience. A notable proportion of students $(78 \%)$ thought that the preparation tests (pre-TBL quizzes) were useful learning activities. Most importantly, the students reported universal agreement $(100 \%)$ that they had a positive attitude towards working with their peers. 


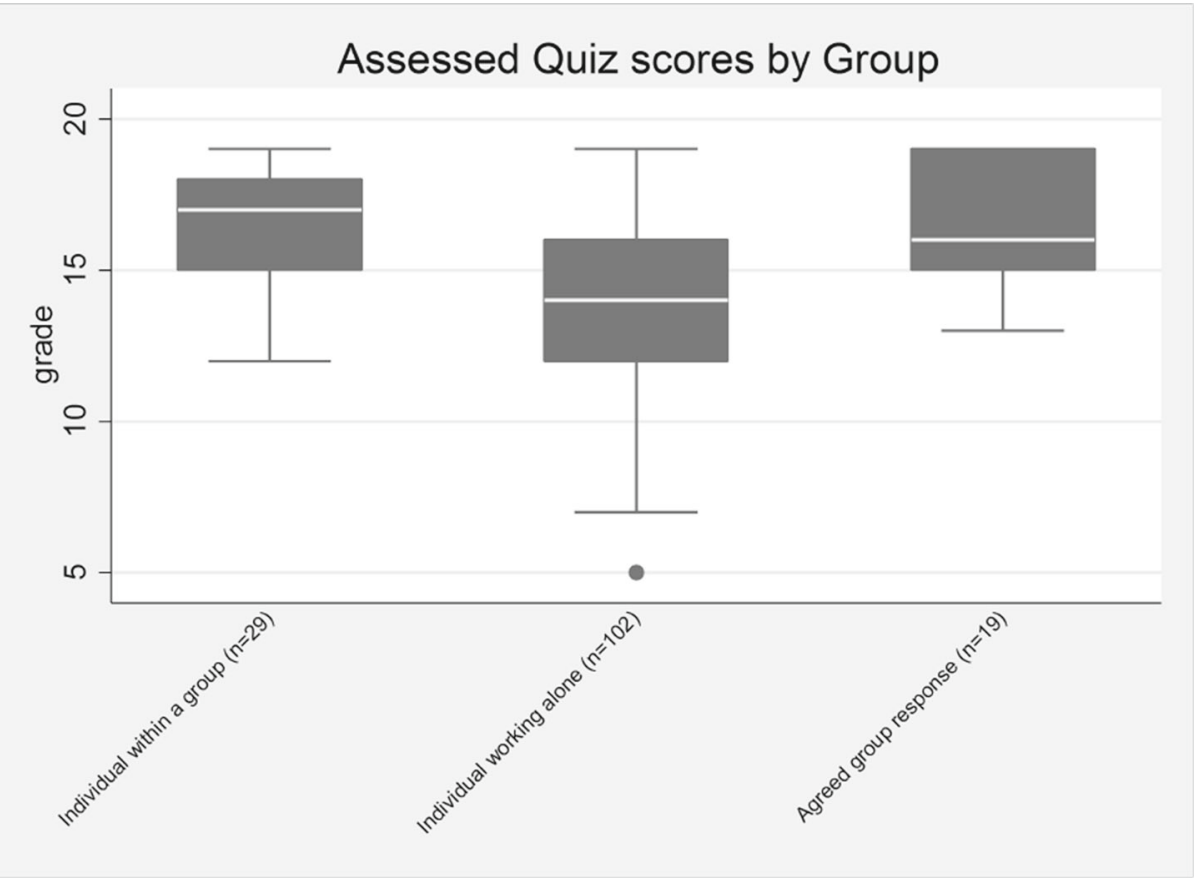

Fig. 4 Boxplot showing median scores for the online quiz in Biostatistics across the 3 groups of Year 1 MD students. Outliers are those subjects further than 1.5 times the IQR from the 25 th or 75 th percentile and are depicted as dots

\section{Discussion}

This study has evaluated the impact of TBL performed across various STEMM disciplines in particular Physics, Engineering and Medicine. In each case, our data supported the use and potential benefits of the flipped classroom combined with TBL. A further limitation is that there were no parallel control groups in two of the cohorts (physics and engineering). Therefore, we cannot ascribe with certainty the improved scores were due only to the teaching approaches. Other factors, such as student ability, quiz content, different tutors in the workshop, could have also caused an improvement in the scores.

Amongst the physics students, the group activity appeared to have had a positive impact on quiz scores throughout the topic with a meaningful increase in scores in each of the four post-TBL quizzes. We found that working in mixed ability groups can promote learning gains for low potential students and that group work brings individuals closer together in terms of their quiz scores. The results from the physics cohort, as shown in Fig. 1, also demonstrate that the improvements in the post-quiz scores were similar for each of the four quizzes when students were placed in mixed ability groups. In our previous study (Parappilly et al. 2015) where we randomly formed permanent student groups, there was improvement in the quiz scores but it was less uniform, the analysis of pre-post testing of 2nd, 4th TBL quizzes of physics cohort showed a significant impact $(p<0.002, p<0.001)$ on their learning whilst there was no notable difference $(p>0.05)$ in the pre- and posttest of quiz 1, 3 by paired $t$ test. As such, this study suggests that grouping mixed ability students increases learning for physics. 
However, given the observational nature of our study, other factors could have also contributed to these increases, and ideally therefore, the impact of TBL needs to also be assessed in comparison with other forms of teaching in a manner in which potential confounding factors are kept constant. In future studies, students could be randomised into group and non-group activity to accurately assess the impact of the group activity.

The results for the engineering cohort suggested that the group work brought students closer together in terms of their expected exam scores. However, the exam results were still strongly associated with the pre-TBL quiz results seen at the start of the topic suggesting that whilst the use of TBL will improve understanding, individual student achievement remains the most important determining factor of final exam scores. In addition, there would be an obvious tendency for the future test scores to overlap across the four groups more than the pre-test scores since the latter were used to define the four groups and there was therefore by definition, no overlap in the scores between the four groups.

Amongst the medical students, there was clear evidence that working within a team provided better learning outcomes than working alone. Post-TBL online quiz scores were significantly higher amongst students who completed the quiz together whether or not they formed their own response for each question or agreed on a group response. This suggests that group discussion of the topic content was an important factor and helped increase understanding and promoted learning. The extent to which this result can be definitively interpreted as demonstrating improved subject knowledge is nonetheless still uncertain. However, given that the quiz questions were closely related to key concepts suggests that these were assimilated well by students with group work.

Finally, the survey results from the engineering cohort indicated that students felt TBL increased their understanding of the key concepts; they had a positive view of TBL. Responses to most statements are in agreement with the previous studies in Physics and Environmental Science (Parappilly et al. 2015). Informal feedback from physics/medical students was very positive with students demonstrating obvious engagement and a very high overall success rate in the relevant exam questions. Our results support the findings of previous studies in the literature (Johnson et al. 1998; Light 2001; Michaelsen et al. 2002; Williams et al. 2007) that students achieve deeper learning and associate increased problemsolving skills with working in groups. Our findings are also in agreement with the findings of Springer et al. (2013) that learning in small group has statistically significant and positive effects on STEMM undergraduate students. It is evident from our results that TBL group work gets students involved in active learning, effective team participation and helps them develop teamwork skills.

\section{Conclusion}

Taken together, our results suggest that the flipped classroom approach together with the use of TBL was associated with positive student outcomes including better student engagement, learning and understanding. The feedback from students has been positive and the implementation of in-class TBL activities as part of Physics and Engineering teaching has improved the participation rate of students in the TBL workshops. In particular, the engineering cohort reported that TBL group work was beneficial to their learning. Similarly, we have seen positive student engagement and feedback from the medical cohort. Informal responses from the medical cohort showed that TBL was perceived positively and helped them engage with the topic content. Its use appears to be effective across a wide variety of STEMM disciplines. Our study therefore adds to previous literature regarding the positive 
impact of TBL and suggests that its use can be applied successfully across all STEMM disciplines, and mixing students in mixed ability groups can promote learning gains for low potential students.

\section{Future Work}

Our TBL approach is currently being adopted in an Optometry topic at Flinders University and we aim to roll out our current TBL group work approaches in STEMM to other universities in Australia.

Acknowledgments This study was supported by a Flinders University Collaborative Research Grant (2014) from the College of Science and Engineering.

Compliance with Ethical Standards This project had ethics approval from Flinders University (Project Number: 5757 SBREC).

Open Access This article is distributed under the terms of the Creative Commons Attribution 4.0 International License (http://creativecommons.org/licenses/by/4.0/), which permits unrestricted use, distribution, and reproduction in any medium, provided you give appropriate credit to the original author(s) and the source, provide a link to the Creative Commons license, and indicate if changes were made.

\section{References}

Ahrensmeier, D., Donev, J.M.K.C., Hicks, R.B., Louro, A.A. (2009). Labatorials at the university of calgary: in pursuit of effective small group instruction within large registration physics service courses. Physics in Canada, 65, 214-216.

Anderson, L., Krathwohl, D., Bloom, B. (2001). A taxonomy for learning, teaching, and assessing: a revision of Bloom's taxonomy of educational objectives. Longman.

Ayala, O.M., Popescu, O., Jovanovic, V.M. (2017). Flipped classroom as blended learning in a fluid mechanics course in engineering technology. In 2017 ASEE Annual Conference \& Exposition, Columbus, Ohio. ASEE Conferences. https://peer.asee.org/28367.

Betta, M. (2015). Self and others in team-based learning: acquiring teamwork skills for business. Journal of Education for Business, 91(2), 69-74.

Bonwell, C., \& Eison, J.A. (1991). Active learning: creating excitement in the classroom. ASHE-ERIC Higher Education Report No. 1.

Boud, D., Cohen, R., Sampson, J. (2001). Peer learning in higher education: learning from and with each other VA: stylus publishing. London: Kogan Page/Sterling.

Burke, A. (2011). Group work: how to use groups effectively. The Journal of Effective Teaching, 11(2), 87-95.

Cooper, J. (1990). Cooperative learning and college teaching: tips from the trenches. Teaching Professor, $4(5), 1-2$.

Davis, B. (1993). Tools for teaching. San Francisco: Jossey-Bass Inc.

Franklin, K., Muir, P., Scott, T., Wilcocks, L., Yates, P. (2010). Introduction to biological physics for the health and life sciences. New York: Wiley.

Freeman, S., Eddy, S., McDonough, M., Smith, M., Okoroafor, N., Jordt, H., Wenderoth, M. (2014). Active learning increases student performance in science, engineering, and mathematics. Proceedings of the National Academy of Sciences. https://doi.org/10.1073/pnas.1319030111.

Georgiou, H., \& Sharma, M. (2015). Does using active learning in thermodynamics lectures improve students' conceptual understanding and learning experiences?. European Journal of Physics, 36(1), $1-13$.

Giancoli, D.C. (2008). Physics for scientists and engineers with modern physics and mastering physics, 4th edn. Boston: Addison-Wesley. 
Griffith, W.T., \& Brosing, J.W. (2002). The physics of everyday phenomena: a conceptual Introduction to Physics, 7th edn. New York: McGraw-Hill.

Hains-Wesson, R. (2007). Peer and self assessment Deakin Learning Futures. Victoria: Deakin University.

Hake, R. (1998). Interactive-engagement versus traditional methods: a six-thousand-student survey of mechanics test data for introductory physics courses. American Journal of Physics, 66(1), 64-74.

Hamdan, N., McKnight, P., McKnight, K., Arfstrom, K.M. (2013). A review of flipped learning.

Hurtubise, L., Hall, E., Sheridan, L., Han, H. (2015). The flipped classroom in medical education: engaging students to build competency. Journal of Medical Education and Curricular Development, 2, JMECD.S23895.

Jakobsen, K., \& Knetemann, M. (2017). Putting structure to flipped classrooms using team-based learning. International Journal of Teaching and Learning in Higher Education, 29(1), 177-185.

Johnson, D.W., Johnson, R., Smith, K. (1998). Active learning: cooperation in the college classroom. Edina: Interaction Book Co.

Johnson, D.W., Johnson, R.T., Smith, K. (2007). The state of cooperative learning in postsecondary and professional settings. Educational Psychology Review, 19(1), 15-29.

Kalman, C.S., Milner-Bolotin, M., Antimirova, T. (2010). Comparison of the effectiveness of collaborative groups and peer instruction in a large introductory physics course for science majors. Canadian Journal of Physics, 88(5), 325-332.

Kalman, C.S., Sobhanzadeh, M., Thompson, R., Ibrahim, A., Wang, X. (2015). Combination of interventions can change students' epistemological beliefs. Phys. Rev. ST Phys. Educ. Res., 11, 020136.

Karanicolas, S., \& Snelling, C. (2010). Making the transition: achieving content connectivity and student engagement through flexible learning tools. In Proceedings of the Distance Education Association of New Zealand (DEANZ) Conference Wellington 2010.

Kerr, B. (2015). The flipped classroom in engineering education: a survey of the research.

Lage, M., \& Platt, G. (2000). The internet and the inverted classroom. Journal of Economic Education, 11.

Landis, R.B. (2000). Studying Engineering (A Road Map to Rewarding Career). Los Angeles: Discovery Press.

Le, X.P., Ma, G.G., Duva, A.W. (2015). Testing the flipped classroom approach in engineering dynamics class. In 2015 ASEE Annual Conference \& Exposition, number 10.18260/p.24841, Seattle, Washington. ASEE Conferences. https://peer.asee.org/24841.

Light, R.J. (2001). Making the most of college: students speak their mind. Harvard University Press: Cambridge.

Michaelsen, L.K., Knight, A.B., Fink, L.D. (2002). Team-based learning: a transformative use of small groups in college teaching. Praeger Publishers, Westport, CT06881, An Imprint of Greenwood Publishing Group Inc.

Michaelson, L.K., \& Sweet, M. (2008). The essential elements of team-based learning. New Directions for Teaching and Learning, 116, 53-59.

Moffett, J. (2015). Twelve tips for "flipping" the classroom. Medical Teacher, 37(4), 331-336.

Morris, J. (2016). The use of team-based learning in a second year undergraduate pre-registration nursing course on evidence-informed decision making. Nurse Education in Practice, 21, 23-28.

Najdanovic-Visak, V. (2017). Team-based learning for first year engineering students. Education for Chemical Engineers, 18, 26-34. Student Recruitment, Expectation and Experience.

Nilsson, J., \& Riedel, S. (2014). Electric Circuits, 10th edn. USA: Pearson Higher Ed.

Parappilly, M., Siddiqui, S., Zadnik, M., Shapter, J., Schmidt, L. (2013). An inquiry-based approach to laboratory experiences: investigating students' ways of active learning. International Journal of Innovation in Science and Mathematics Education, 21(5), 42-53.

Parappilly, M., Schmidt, L., Ritter, S.D. (2015). Ready to learn physics: a team-based learning model for first year university. European Journal of Physics, 36(5), 055052.

Parappilly, M., Hassam, C., Woodman, R.J. (2018). Race to improve student understanding of uncertainty: using lego race cars in the physics lab. American Journal of Physics, 86(1), 68-76.

Parmelee, D.X., \& Michaelson, L.K. (2010). Twelve tips for doing effective team-based learning (tbl). Medical Teacher, 32(2), 118-122.

Raudenbush, S.W., \& Bryk, A. (2002). Hierarchical linear models: applications and data analysis methods, 2nd edn. Housand Oaks: Sage.

Scicluna, H.A., O’Sullivan, A.J., Boyle, P., Jones, P.D., Patrick McNeil, H. (2015). Peer learning in the unsw medicine program. BMC Medical Education, 15(1), 167.

Singer, J.D., \& Willett, J.B. (2003). Applied longitudinal data analysis: modelling change and event occurrence. New York: Oxford University Press.

Springer, L., Stanne, M.E., Donovan, S.S. (2013). Effects of small-group learning on undergraduates in science, mathematics, engineering, and technology: a meta-analysis. Review of Educational Research, 69(1), 21-51. 
Tai, J.H.-M., Haines, T., Canny, B., Molloy, E. (2014). A study of medical students' peer learning on clinical placements: what they have taught themselves to do. Journal of Peer Learning, 7, 57-80.

Topping, K.J. (2005). Trends in peer learning. Educational Psychology, 25(6), 631-645.

Urone, P.P. (2001). College Physics, 2nd edn. Belmont: Thomson Learning, Inc.

Vasan, N., DeFouw, D.O., Compton, S. (2009). A survey of student perceptions of team-based learning in anatomy curriculum: favorable views unrelated to grades. Anatomical Sciences Education, 2, 150-155.

Watkins, J., \& Mazur, E. (2009). Using jitt with peer instruction. In Just in time teaching across the disciplines.

Williams, B.C., He, B., Elger, D.F., Schumacher, B.E. (2007). Peer evaluation as a motivator for improved team performance in bio/ag engineering design classes. International Journal of Engineering Education, 23(4), 698-704.

Yelamarthi, K., \& Drake, E. (2015). A flipped first-year digital circuits course for engineering and technology students. IEEE Transactions on Education, 58(3), 179-186.

Publisher's Note Springer Nature remains neutral with regard to jurisdictional claims in published maps and institutional affiliations. 